\title{
RETRACTIONS
}

\section{Abnormal gene expression and gene fusion in lung adenocarcinoma with high-throughput RNA sequencing}

ZH Yang, R Zheng, Y Gao, Q Zhang and H Zhang

Cancer Gene Therapy (2016) 23, 72; doi:10.1038/cgt.2015.69; published online 18 December 2015

Retraction to: Cancer Gene Therapy (2014) 21, 74-82; doi:10.1038/ cgt.2013.86

The Publisher and Editor retract this article in accordance with the recommendations of the Committee on Publication
Ethics (COPE). After a thorough investigation we have strong reason to believe that the peer review process was compromised.

The original article was published online on 7 February 2014.

\section{Screening genes crucial for pediatric pilocytic astrocytoma using weighted gene coexpression network analysis combined with methylation data analysis}

H Zhao, W Cai, S Su, D Zhi, J Lu and S Liu

Cancer Gene Therapy (2016) 23, 72; doi:10.1038/cgt.2015.70; published online 18 December 2015

Retraction to: Cancer Gene Therapy (2014) 21, 448-455; doi:10. 1038/cgt.2014.49

The Publisher and Editor retract this article in accordance with the recommendations of the Committee on Publication
Ethics (COPE). After a thorough investigation we have strong reason to believe that the peer review process was compromised.

The original article was published online on 26 September 2014. 